\title{
СИСТЕМА ПІДТРИМКИ ПРИЙНЯТТЯ РІШЕНЬ ПРИ ПРОВЕДЕННІ ВІТРЕКТОМІЇ У ПАЦІЄНТІВ ІЗ ПРОЛІФЕРАТИВНОЮ ДІАБЕТИЧНОЮ РЕТИНОПАТІЄЮ
}

Національна медична академія післядипломної освіти імені П. Л. Шупика

\begin{abstract}
У статті розглядаються питання допомоги сімейним лікарям у прийнятті рішень щодо можливості оперативного лікування хворих на діабетичну ретинопатію. Описуються підходи до побудови системи прогнозування результату хірургічного лікування (вітректомії) та ризику виникнення ускладнень, що сприятиме об'єктивізації індивідуальної оцінки ризику для пацієнта та дасть можливысть оптимізувати надання офтальмологічної допомоги хворим із проліферативною діабетичною ретинопатією.
\end{abstract}

Ключові слова: прогнозування, сімейна медицина, система підтримки прийняття рішень, діабетична проліферативна ретинопатія, вітректомія.

\section{СИСТЕМА ПОДДЕРЖКИ ПРИНЯТИЯ РЕШЕНИЙ ПРИ ПРОВЕДЕНИИ ВИТРЭКТОМИИ У ПАЦИЕНТОВ С ПРОЛИФЕРАТИВНОЙ ДИАБЕТИЧЕСКОЙ РЕТИНОПАТИЕЙ}

\author{
А. Н. Рубан \\ Национальная медицинская академия последипломного образования имени П. Л. Шупика \\ В статье рассматриваются вопросы помощи семейным врачам в принятии решений относительно возможности \\ оперативного лечения больных диабетической ретинопатией. Описываются подходы к построению системы про- \\ гнозирования результата хирургического лечения (витректомии) и риска возникновения осложнений, что будет \\ способствовать объективизации индивидуальной оценки риска для пациента и позволит оптимизировать оказание \\ офтальмологической помощи больным с пролиферативной диабетической ретинопатией.
}

Ключевые слова: прогнозирование, семейная медицина, система поддержки принятия решений, диабетическая пролиферативная ретинопатия, витрэктомия.

\section{APPROACHES TO THE CONSTRUCTION OF THE VITRECTOMY RISK MANAGEMENT SYSTEM IN PATIENTS WITH PROLIFERATIVE DIABETIC RETINOPATHY}

A. M. Ruban

\section{Shupyk National Medical Academy of Postgraduate Education}

The article presents the some approaches to create a system support of making decision during vitrectomy in patients with diabetic proliferative retinopathy, promotes objective assessment of individual risk-management for patient and allows optimize ophthalmological care for them.

Key words: prediction, family medicine, system support of making decision, predictive factors, diabetic proliferative retinopathy, vitrectomy.

Введение. Оказание помощи пациентам, страдающим офтальмологическими заболеваниями, имеет большое значение, учитывая, что семейные врачи еще недостаточно владеют логикой принятия решений. На сегодняшний день, наиболее эффективным методом лечения осложненных форм пролиферативной диабетической ретинопатии (ПДР) является комплексное витреоретинальное вмешательство, которое заключается в удалении стекловидного тела, иссечении фиброваскулярных мембран, расправле-

(C) А. М. Рубан 
нии и эндолазеркоагуляции ишемической сетчатки $[1,2]$. Вместе с тем, результат хирургического лечения пациентов с ПДР остается недостаточно прогнозируемым и определяется многими, не до конца изученными факторами [3, 4]. Существующие в настоящее время офтальмологические рекомендации (в том числе и хирургического) ведения больных сахарным диабетом (СД), характеризуют лишь общие лечебно-диагностические принципы или рассматривают только отдельные варианты течения заболевания, не учитывая все разновидности проявлений патологического процесса диабетического поражения сетчатки.

Цель исследования: обоснование и построение системы управления тактикой и стратегией лечения больных с пролиферативной диабетической ретинопатией с учетом прогностической ценности различных клинических признаков, как факторов риска исхода хирургического лечения пациентов.

Материалы и методы исследования. Проведено ретроспективное исследование 145 операций (витректомий) в неселективной когорте 145 пациентов (145 глаз) с ПДР для определения возможных прогностических факторов исхода и осложнений операций. Все больные исследованы и оперированы в Киевской городской клинической офтальмологической больнице «Центра микрохирургии глаза».

Общую группу составили пациенты с витретинальным кровоизлиянием, тракционной или тракционно-регматогенной отслойкой сетчатки. В группу не вошли пациенты с первичной регматогенной отслойкой сетчатки, увеитом или травмой. Минимальный срок наблюдения составил 6 месяцев. В группу отобрали мужчин 62 (42,7 \%), женщин - 83 (57,3 \%); 89 (62\%) пациентов имели 1 -й тип сахарного диабета, 56 (38 \%) - 2-й тип. Продолжительность диабета $>15$ лет отмечена у 137 (95\%) пациентов, и $<15$ лет у 8 (5\%). Возраст пациентов - от 17 до 75 лет; 49 пациентов (34\%) были моложе 50 лет, 96 пациентов (66 \%) - старше 50 лет.

Дооперационное обследование включало: определение остроты зрения, биомикроскопию, офтальмоскопию, статическую и динамическую периметрии, тонометрия, ультразвуковое сканирование (при невозможности осмотра глазного дна), флуоресцентную ангиографию (для определения макулярной ишемии сетчатки), оптическую когерентную томографию (для диагностики макулярного отека, разрыва, витреомакулярной тракции). Остроту зрения определяли по таблице Сивцева - Головина.
Операции выполнялись по методу трехпортовой витрэктомии (с моно- или бимануальной техникой) с использованием различных калибров инструментов 20/23/25G. Удалялось центральное стекловидное тело, проводилось устранение передне-задних тракций и максимально полное удаление фиброваскулярных мембран и задней гиалоидной мембраны техникой деламинации, сегментации или иссечения «единым блоком». При необходимости проводилась панретинальная эндолазеркоагуляция. Для визуализации глазного дна использовали широкоугольную систему BIOM (Oculus, Germany) или OFFISS (Topcon, Japan). При необходимости проведения хирургических манипуляций на макулярной области сетчатки нами использовались контактные линзы (Dorc, Netherlands). В большинстве случаев проводилась одновременная факоэмульсификация хрусталика с имплантацией мягкой интраокулярной линзы (ИОЛ). Силиконовая или газовая тампонада проводилась по показаниям [5].

Поиск «факторов риска» определялся вероятностью возникновения неудовлетворительного конечного функционального результата операции при наличии или отсутствии признака. Вычисление прогностической значимости признаков основывалось на методике Н. М. Амосова с соавторами (1972) и заключалось в сравнении частоты неблагоприятного исхода у больных при наличии исследуемого признака с частотой неблагоприятного исхода у всех больных, обследованных на данный показатель. В системе прогнозирования анализировали более 100 признаков, с учетом данных анамнеза, клинического обследования, лабораторных, специальных и инструментальных методов и 60 видов осложнений (12 - интраоперационных; 23 вида, возникших в раннем послеоперационном периоде, 25 видов, отмеченных в позднем послеоперационном периоде) $[6,7]$.

Результаты исследования и их обсуждение. Многочисленные операционные риски обусловливают условия неопределенности в принятии решений хирургом. Наибольшие трудности при построении системы управления рисками в ситуациях неопределенности заключаются в выработке правил принятия решений, построении оптимального плана обследования пациентов, выборе оптимального (в смысле минимизации осложнений) метода лечения и обосновании профилактических мероприятий.

Прогнозирование операционных рисков всегда связано с реально существующим процессом. 
Зависимость неблагоприятного исхода операции от суммы баллов риска

\begin{tabular}{|c|c|c|c|c|}
\hline \multirow{2}{*}{ Сумма баллов } & \multicolumn{4}{|c|}{ Количество наблюдений } \\
\cline { 1 - 5 } & \multirow{2}{*}{ Всего } & \multicolumn{2}{|c|}{ из них с неблагоприятным исходом } \\
\cline { 2 - 5 } & & абс. & $\%$ & m \\
\hline$<5$ & 30 & 2 & 6,0 & 3,6 \\
\hline $6-10$ & 30 & 3 & 25,0 & 4,8 \\
\hline $11-15$ & 36 & 9 & 70,0 & 9,3 \\
\hline $16-20$ & 35 & 25 & 90,0 & 9,0 \\
\hline $21-25$ & 10 & 9 & 100 & 9,8 \\
\hline$>26$ & 4 & 4 & 35,9 & 3,9 \\
\hline
\end{tabular}

В этом случае ход процесса в последующие моменты времени определяется не только значением показателей в определенный момент времени, но и всей реализацией в предыдущие моменты времени - так называемой предысторией [8].

Для определения структуры прогностической системы при витреоретинальном вмешательстве необходимо создать априорную классификацию состояний и симптомов (медицинское обеспечение) и обосновать последовательность этапов прогнозирования их последствий. Для решения задачи прогнозирования на практике применялись относительно простые методики, связанные с бальными критериями, при которых одно из ведущих мест занимает определение прогностической значимости клинических признаков. Поэтому важнейшей задачей в процессе создания системы управления рисками было выделение и систематизация признаков, имеющих наибольшее значение для течения и исхода патологического процесса, которые были предварительно сгруппированы врачом. На основа- нии исследования и анализа 145 клинических признаков и 60 видов осложнений нами было отобрано 33 фактора, характеризующих общее состояние и офтальмологический статус пациента, и наиболее важных для прогнозирования исхода операции [9].

Наиболее значимые показатели были объединены в карту риска. Перед составлением карты риска проверялась взаимосвязь (корреляция) параметров. При наличии последней выбирался один из них или уменьшалась ценность обоих параметров. Экспериментальную проверку карты риска проводили на трех выборках: «учебной» выборке (80 пациентов), куда входят наблюдения с верифицированным исходами, «контрольной» выборке (25 пациентов) которая объединяет наблюдения с проверенными диагностическими выводами, и «экзаменационной» выборке по историям болезни 30 пациентов, где истинность выводов проверялась апостериорно.

Группы пациентов подбирались с верифицированными результатами. Прогноз определяли

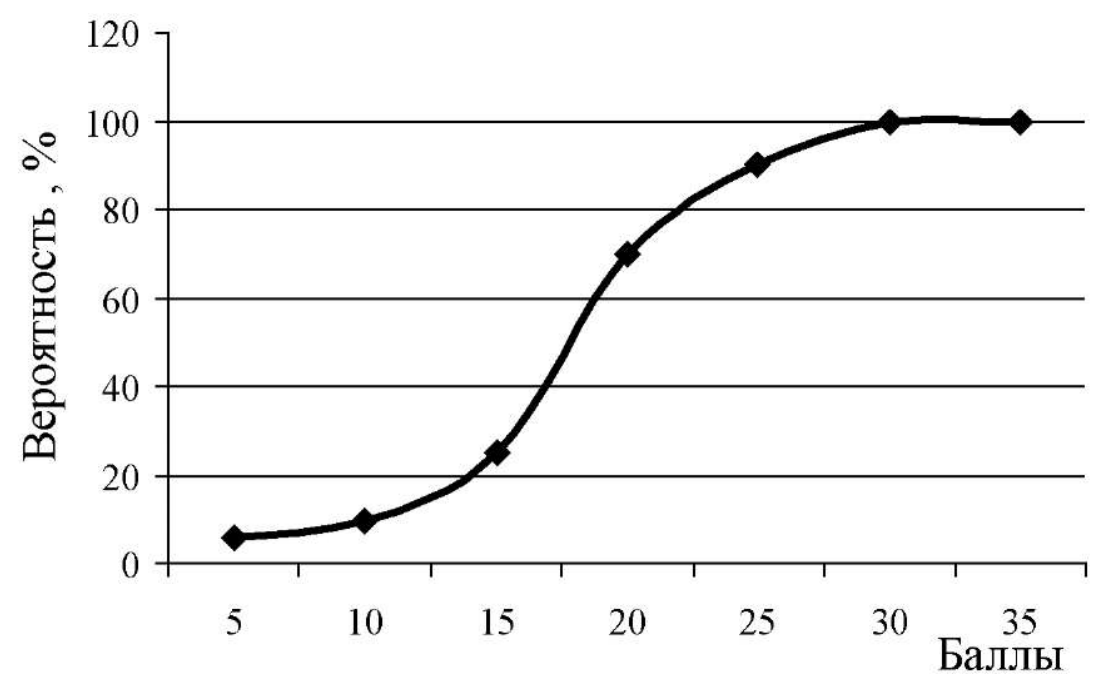

Рис. 1. Зависимость вероятности неблагоприятного исхода витрэктомии от суммы баллов риска 
суммой баллов, характеризующих интегральную прогностическую ценность факторов, по результатам анализа зависимости вероятности неблагоприятного исхода операции (витрэктомии) от суммы баллов риска (табл. 1).

Причем зависимость носит существенно нелинейный характер и имеет s-образный характер (рис. 1).

На практике использовать построенные кривые неудобно, поэтому нами было предложено выделять четыре степени риска.

Технология их выделения, вообще говоря, зависит от пологости (наклона) кривой. Применение степеней тяжести (что эквивалентно риску оперативного вмешательства) дает возможность провести интегральную оценку тяжести состояния пациента и на ее основе выбрать оптимальную тактику лечения. Кроме того, оценка суммарного риска является необходимым компонентом при разработке рекомендаций в профилактической офтальмологии, особенно в индивидуальной профилактике, или, как определяют эксперты ВОЗ, в стратегии высокого риска, когда объектом профилактического вмешательства является конкретный пациент или небольшая группа (когорта) пациентов, имеющих сходные характеристики по основным факторам, которые влияют на прогноз операции.

Анализ информации о пациенте (риск-менеджмент) при планируемой витрэктомии должен проводиться последовательно, в заранее установленные сроки. На каждом последующем этапе необходимо сделать прогноз дальнейшего состояния и ожидаемого результата. Такой клинический мониторинг как система наблюдения, анализа, оценки и прогноза состояния больных является с одной стороны средством управления рисками, a с другой - системой поддержки принятия решений. В итоге, достигаются три цели: 1) оперативное и эффективное решение вопросов тактики проведения витрэктомии при ПДР; 2) обоснование профилактического лечения возможных осложнений; 3) предоставление объективных количественных характеристик риска операций для пациента.

Выводы. 1. Повышение требований к управлению состоянием пациента, сопровождающееся увеличением объема информации, определяет необходимость применения информационных технологий для прогнозирования течения и результата лечебного процесса у пациентов с ПДР в режиме реального времени.

2. Разработка и внедрение системы прогнозирования рисков неблагоприятного результата и возникновения осложнений хирургического лечения способствует объективизации индивидуальной оценки рисков для каждого пациента, позволяет обосновать время проведения оперативного вмешательства и оптимизировать оказание офтальмологической помощи больным с сахарным диабетом.

\section{Литература.}

1. Глинчук Я. И. Клинические результаты применения жидких перфторорганических соединений в комплексном хирургическом лечении тракционных отслоек сетчатки с захватом макулярной области при пролиферативной диабетической ретинопатии / Глинчук Я. И., Метаев С. А., Саркисян А. И. //Офтальмохирургия. - 1996. - № 2. - С. 7-12. 2. Oshima Y. Surgical outcomes of 25-gauge transconjunctival vitrectomy combined with cataract surgery for vitreoretinal diseases / Oshima Y., Ohji M., Tano Y. // Ann Acad Med Singapore. - 2006. - Vol. 35. - P. 175-180.

3. Родин С. С. Бевацизумаб (авастин) в комплексном хирургическом лечении больных с пролиферативной стадией диабетической ретинопатии / Родин С. С., Асланова В. С. // Український медичний альманах. - 2008. - Т. 11, № 3. C. $126-128$.

4. Рубан А. М. Результати комбінованої 23G-вітректомії з факоемульсифікацією та імплантацією ІОЛ у пацієнтів на проліферативну діабетичну ретинопатію / А. М. Рубан // Офтальмологічний журнал. - 2013. - № 2. - С. 36-42. 5. Рубан А. М. Бімануальна мініінвазивна техніка видалення заднього вітреошизису у пацієнтів на проліферативну діабетичну ретинопатію / А. М. Рубан // Зб. наук. праць співробіт. НМАПО імені П. Л. Шупика. К., 2013. - № 22 (4). - С. 90-98.

6. Рубан А. М. Інформаційне забезпечення стратегії визначення оптимальної тактики хірургічного лікування хворих 3 проліферативною діабетичною ретинопатією / А. М. Рубан // Медична інформатика та інженерія. - 2011. - № 3. C. $56-62$.

7. Минцер О. П. Інформаційні технології в хірургії / Минцер О. П., Москаленко В. З., Веселий С. В. - В 10 кн. «нфформаційні технології в охороні здоров'я і практичній медицині». - Кн. 3. - К. : Вища школа, $2004 .-423$ с.

9. Риков С. О. Фактори ризику в прогнозуванні виходу хірургічного лікування проліферативної діабетичної ретинопатії / Риков С. О., Рубан А. М., Зольнікова А. Ю. // Медична інформатика та інженерія. - 2012. - № 1. C. $16-22$.

10. Oda H. Recent outcomes of vitreous surgery for diabetic retinopathy / Oda H., Konno K., Mitsui K. et al. // Nippon Ganka Gakkai Zasshi. - 2005. - Vol. 109. - P. 603-612. 